\title{
A Política de Interiorização da Universi- dade Federal do Pará no Município de Cametá - $\mathrm{PA}^{1}$
}

\section{The Politics of Interiorization of Federal University of Pará In The Cametá City - PA}

\author{
Ana Lúcia Bentes DIAS * \\ Maria do Socorro da C. COELHO ** \\ Fábio Augusto Fiel SANTOS***
}

RESUMO

A partir do Projeto de Interiorização do Ensino Superior, o estudo busca analisar qual a contribuição da Universidade Federal do Pará - UFPA para o desenvolvimento econômico do município de Cametá - PA e verificar se existe relação do referido projeto com a política desenvolvimentista do Governo Federal.

Palavras-chave: universidade - UFPA - interiorização do ensino superior - desenvolvimento.

\section{ABSTRACT}

By the Project of Interiorization of Superior Teaching, the study tries to analyze what the contribution of Federal University of Pará - UFPA for the economic development of Cametá City - PA and verify if there is relation about this project to the developmental politics of Federal Government.

Key word: university - UFPA - interiorization of superior teaching - development.

\footnotetext{
${ }^{1}$ Texto elaborado a partir da pesquisa "Interiorização da UFPA no Baixo Tocantins: O Balanço de uma Proposta", apresentada no XVI EPENN/2003.

* Mestre em Educação pela UNIMEP-SP. Professora Assistente II do Campus de Castanhal, da UFPA. E-mail: anluci@amazon.com.br

*** Mestre em Educação pela UNIMEP-SP. Docente do Centro de Educação da UFPA. Coordenadora do Grupo de Estudos e Pesquisas sobre Estado e Educação na Amazônia GESTAMAZON. E-mail: mscc@ufpa.br

*** Graduado em Ciências Sociais (Licenciatura Plena) pela UFPA. Bolsista de Iniciação Científica do Grupo de Estudos e Pesquisas sobre Estado e Educação na Amazônia GESTAMAZON. E-mail: fabio2001fiel@bol.com.br
}

Olhar de professor, Ponta Grossa, 7(2): 35-46, 2004. 
$\mathrm{O}$ interesse das pesquisadoras em um estudo centrado na interiorização da Universidade Federal do Pará na área do Baixo Tocantins, em especial no município de Cametá - PA, devese ao fato de ambas terem familiaridade com o tema, uma vez que o Grupo de Estudos e Pesquisa sobre Estado e Educação na Amazônia GESTAMAZON, ao qual são vinculadas, vem desenvolvendo estudos sobre a política de Interiorização do Ensino Superior na Amazônia. A opção pelo município locus do trabalho justifica-se a partir da prática docente e de pesquisa do GESTAMAZON no Campus da UFPA, no referido município. Tal experiência provocou inquietações e as decorrentes indagações:

- A partir de seu processo de interiorização do ensino superior, qual a contribuição da Universidade Federal do Pará (UFPA) para com o desenvolvimento econômico do município de Cametá, no Pará?

- Existe relação do Projeto de Interiorização da UFPA com a política desenvolvimentista do Governo Federal?

Os passos metodológicos adotados incluíram pesquisa em fontes bibliográficas, análise documental referente ao objeto de estudo e entrevistas com representantes de órgãos ou entidades responsáveis pela economia local, como a Colônia de Pescadores, a Secretaria Municipal de Agricultura de Cametá (SEMAGRI), a Empresa de Assistên- cia e Extensão Rural (EMATER), a Colônia de Agricultores (produtores de farinha) e, ainda, com egressos da Licenciatura Plena em Pedagogia (curso mais ofertado pela UFPA naquele município).

\section{AINTERIORIZAÇÃODAUFPAE A POLÍTICA DESENVOLVIMEN- TISTANAAMAZÔNIA}

A política de Interiorização das Universidades da Amazônia surge a partir da pressão social do povo interiorano e da grande organização política, o que contribuiu para o esgotamento do regime militar. A luta por liberdade trazia em seu bojo o desejo de democratizar as instâncias do Estado, entre elas a Universidade.

Em 1986, por intermédio do Projeto Norte de Interiorização (I PNI), a UFPA implantou os cursos de licenciatura plena em Geografia, História, Matemática, Letras e Pedagogia em oito municípios do Pará - Altamira, Abaetetuba, Bragança, Castanhal, Cametá, Marabá, Soure e Santarém. O estudo em questão desenvolveu-se em Cametá.

No decorrer do estudo, detectamos que a política de interiorização da UFPA estava intrinsecamente relacionada com a ação desenvolvimentista do Governo Federal e com a proposta deste de tornar a Amazônia uma área de importância estratégica à integração da economia nacional, de modo a possibilitar o avanço da fronteira econômica

Olhar de professor, Ponta Grossa, 7(2): 35-46, 2004. 
do país e a integração do mercado nacional, tornando a região grande fornecedora de recursos ao capital nacional e internacional ${ }^{1}$

A relação dessas políticas fica mais evidente quando, a partir do Consenso de Washington, em 1989, em que os organismos internacionais como o Banco Mundial orientavam que o Estado Nação reduzisse gastos nas áreas sociais, o governo brasileiro investiu na oferta de cursos superiores, expandindo suas funções sobretudo no interior do país, fato esse que ia de encontro à lógica dos organismos internacionais.

A política de interiorização resulta de um documento elaborado pelo Ministério da Educação e CulturaMEC em 1985, no qual o governo brasileiro apresenta um diagnóstico do ensino superior no país. O relatório aponta a necessidade de a Universidade descentralizar suas funções e manter maior relação com a sociedade. Houve por parte do MEC várias iniciativas nesse sentido, visando a democratizar o acesso ao ensino superior, entre elas a interiorização desse ensino.

A expansão do ensino superior deu-se, naquele momento, pelo fato de o Governo acreditar que a qualificação da mão-de-obra era necessária ao sucesso dos projetos pensados para a Amazônia e para o Brasil naquela conjuntura. Dessa forma, argu- menta-se que o ritmo e a direção do desenvolvimento das políticas educacionais estão relacionados com o alargamento dos mecanismos de controle social, bem como com o nível de desenvolvimento das forças e das relações de produção (CAMARGO, 1997).

Portanto, o projeto de interiorização do ensino superior no interior na Amazônia está em consonância com o projeto desenvolvimentista do governo federal. As primeiras ações de interiorização do ensino superior no interior da Amazônia deram-se na década de 70, com a criação do CRUTAC (Centros Rurais Universitários de Treinamento e Ações Comunitárias), o desenvolvimento do Projeto Rondon e o incentivo à instalação de campus universitários avançados - provenientes de outros estados brasileiros no interior de alguns municípios da Amazônia.

Posteriormente surgem os Projetos Norte de Interiorização (I PNI, 1986/1989; II PNI, 1994/1997 e III PNI, 1997/2001), numa época em que se desenvolve grande política industrial para o país, tendo na Amazônia uma das principais bases de apoio dessa política.

Através da execução do II PNI, podemos observar um caráter institucionalizado na sua ação, procurando dar continuidade às expec-

${ }^{1}$ Ver I PDA ( I Plano de Desenvolvimento da Amazônia 1972- 1974). 
tativas do I PNI. Nessa fase de atuação, mostra-se a presença mais clara do Estado Nacional e dos organismos internacionais, que priorizam o desenvolvimento de uma educação voltada principalmente à preparação de mãode-obra e de recursos humanos para o desenvolvimento da região, atendendo assim a uma nova fase do capitalismo.

Com a implantação do modelo econômico industrial, novas prioridades surgem no contexto da economia nacional. Dentre elas, aparece com grande força a qualificação da mão-de-obra e o desenvolvimento de projetos que pudessem sanar as carências materiais e de mercado do centro-sul do país.

De acordo com essa realidade, apresentava-se como alternativa de solução viável a integração da Amazônia ao espaço de acumulação do capital do centro-sul do país. No bojo dessa política, o objetivo prioritário era integrar o mercado interno conforme as necessidades de expansão e superação das dificuldades da economia nacional. Dessa forma, conforme Lobo (1996, p. 85), surge a necessidade de:

(...) eliminação, se possivel, de todas as barreiras existentes à livre movimentação econômica entre as regiões do país. Mais que isso, haveria que aumentar-se o grau de interdependência regional, através de um significativo aumento da complementaridade econômica inter-regional.

É nesse contexto de expansão e modificação da estrutura econômica do país que a Amazônia entra na pauta dos grandes projetos do governo, tendo seus reflexos nos diversos municípios da região, dentre eles Cametá. Naquele momento, a expansão do ensino superior para o interior da Amazônia parecia ganhar maiores dimensões.

A política desenvolvimentista do Governo Federal para a região elegeu algumas áreas como sendo prioritárias ao desenvolvimento do projeto de integração da grande área verde ao espaço da economia nacional, modificando essa grande porção de terra virgem de espaço natural em espaço funcional(BECKER, 1982).

Dentre as áreas tidas como prioritárias ao projeto desenvolvimentista do Poder Executivo Central estavam os estados do Acre, do Amazonas, de Rondônia, dos antigos Territórios do Amapá e de Roraima, e o estado do Pará, abrangendo a microrregião de Santarém, formada pelos municípios de Faro, Juruti, Óbidos, Monte Alegre, Alenquer, Oriximiná e pela porção oriental do Arquipélago do Marajó, além das sub-regiões do Baixo Tocantins (onde está localizado o município de Cametá), da Guajarina, da Bragantina, do Salgado e da área metropolitana de Belém. (IPDA, 1972/ 1974).

As áreas mencionadas não foram selecionadas aleatoriamente, e sim de acordo com sua relevância econômico-social e com a sua localização geográfica no espaço amazônico. Foram escolhidas de forma planejada e cau- 
telosamente estudadas, assim como o projeto político-econômico nacional desenvolvido pelo poder executivo no espaço brasileiro.

Diante de tal política, mudanças foram percebidas nessas áreas, seja no seu aspecto econômico, político ou social. Analisando o aspecto econômico, observa-se que em Cametá são grandes as influências dessa política, principalmente pelo fato de a cidade estar localizada em uma área considerada estratégica, segundo estudos realizados pelo Governo Federal.

Em análise dos mapas contidos no I PDA, observam-se as áreas consideradas de maior importância à execução do projeto desenvolvimentista do Governo Federal: Cametá está situada entre os centros propulsores indicados como de relevância impar a tal projeto.

Os projetos do Poder Executivo desenvolvidos na região amazônica trouxeram resultados negativos e positivos para a região, articulados que estavam às políticas do capital internacional. Muitos desses projetos desarticularam os rumos da economia de alguns municípios da região, na medida em que ignoravam os planos de desenvolvimento local e prejudicavam os rumos e o andamento daquela economia em particular.

$O$ fato evidencia que os interesses dos agentes públicos e privados da região foram desconsiderados no processo de implantação e execução dos grandes projetos, tendo eles que se adaptarem aos interesses da política nacional (LOBO, 1996).

O autor acima argumenta que, quando houve oportunidade de se ter maior participação no processo de decisão das políticas públicas para a região e, conseqüentemente, de se tirar maiores benefícios dessas políticas, o poder local apresentou-se incapaz ou desinteressado em criar tais oportunidades e, assim, tentar conseguir para a Amazônia algum fruto positivo daquela ação desenvolvimentista, principalmente no caso do Pará:

(...) houve uma incapacidade do bloco de poder local de formular um projeto alternativo ao da instância federal ou de, pelo menos, de inserir-se neste de forma mais avançada. (LOBO, 1996, p. 101).

\subsection{A Interiorização da UFPA em Cametá}

No bojo da política desenvolvimentista na Amazônia constava o município de Cametá, localizado geograficamente nas áreas selecionadas como prioritárias e estratégicas à execução dessa política. Às margens do Baixo Tocantins, no estado do Pará, fica o referido município, criado em 24 de outubro de $1848^{2}$, pela Lei n. ${ }^{\circ} 145$. Esse município foi direta-

${ }^{2}$ A fundação da cidade de Cametá data de 1617, quando era habitada pelos índios Caamutá, palavra que dá origem ao nome da mesma. Só em 1848 a cidade sai da situação de Comarca e legalmente é transformada em município. 
mente atingido, em sua economia, pelas políticas do Governo Federal para a Amazônia.

Desde a sua criação, Cametá abrigou em seu território uma elite econômica e culturalmente conservadora. Foi, inclusive, o primeiro município do interior da Amazônia a aderir à independência do Brasil, em 1823. Em 1835, destacou-se como importante na contribuição de resistência ao movimento popular ocorrido na Província do Pará, entre brasileiros e portugueses, conhecido como Cabanagem.

Passados mais de três séculos de sua existência, Cametá ainda vive sob forte política oligárquica. As oligarquias mostram-se mais preocupadas em garantir seus próprios interesses, não criando políticas de geração de empregos e bem-estar social à população. Dessa forma, comprometem a dignidade social e o desenvolvimento local do município.

Há quase um século, o município de Cametá vem sendo dirigido por três poderosas oligarquias - os Mendonças, os Parijós e os Peres que, freqüentemente, no jogo dos interesses políticos, posicionam-se ao lado das políticas do Governo Federal, mais preocupados que estão em manter seu status quo, abandonando a população, carente de políticas sociais (CARVALHO, 1998)

Destacamos que nas últimas eleições para Prefeito, em Cametá venceu o Partido dos Trabalhadores; durante os 386 anos da existência da cidade de Cametá, é a primeira vez que um partido vinculado aos movimentos sociais chega ao poder.

Diante do projeto desenvolvimentista que envolve com grande peso a Amazônia, Cametá foi diretamente atingida em sua economia pelas ações do Estado desenvolvimentista, vindo a sofrer negativamente os custos dessa ação. Dentre esses custos estão as conseqüências ambientais provocadas pela construção da Hidrelétrica de Tucuruí, que ocasionou o desmatamento e o desaparecimento de alguns tipos de pescado importante para o consumo, afetando diretamente a economia local.

A agricultura, a pecuária, o extrativismo e a pesca estão entre as principais atividades econômicas de Cametá, sendo a última (a pesca), a mais prejudicada com as ações do governo. Na sua hidrografia destacase o rio Tocantins, onde se desenvolve grande atividade pesqueira. Com uma extensão de 2.690 km, é o rio mais importante para o município.

A pesca representa a principal atividade econômica e de sobrevivência das famílias do município, sobretudo a pesca artesanal. Essa atividade enfrenta grandes problemas estruturais, como a falta de uma infra-estrutura adequada de conservação e armazenamento do pescado, frigoríficos e outros recursos necessários ao desenvolvimento da atividade. Tais deficiências dificultam o trabalho das famílias que vivem da pesca (CARVALHO, 1998, p. 53). Além da pesca, 
a atividade de produção de farinha de mandioca e o plantio da pimenta-doreino e do arroz formam as atividades econômicas que mais ocupam a população economicamente ativa (PEA).

Feita uma caracterização das principais atividades econômicas desenvolvidas no município e a relação dessas atividades com as políticas do poder executivo nacional para a Amazônia, fica evidente que a economia de Cametá saiu fortemente abalada com tais políticas e que, ao contrário do que esperava o povo cametaense, a universidade não tem conseguido corresponder às expectativas daquela sociedade, principalmente quando se trata de seu desenvolvimento econômico.

Essa realidade mostra-se presente em documentos analisados e é confirmada no decorrer da pesquisa de campo, onde obtivemos informações vindas de setores econômicos e institucionais localizados no município de Cametá, a respeito das ações da UFPA no município e do desenvolvimento econômico local.

\section{ALGUNS RESULTADOS}

Com a chegada da universidade em alguns municípios da região amazônica, essa instituição de ensino superior passa a ser vista como possibilidade alavancadora do desenvolvimento econômico e social dos mesmos. Contudo, nem sempre os resultados alcançados são os esperados, uma vez que a universidade não vem conseguindo corresponder às necessidades mais urgentes da população desses municípios.

Com a política desenvolvimentista do Governo Federal, a economia de Cametá foi atingida de forma negativa. Em alguns setores, essa negatividade é visível. Esse é o caso da produção pesqueira do município, uma das atividades mais importantes para a economia local, que foi fortemente sacrificada com as políticas dos grandes projetos implementadas pelo Poder Executivo na Amazônia, principalmente com a criação da hidrelétrica de Tucuruí.

Com a construção da hidrelétrica, a atividade pesqueira do município foi atingida diretamente, pois os peixes que antes passavam para o município ficam agora presos nas barragens da represa. Tal fato trouxe conseqüências sociais visíveis à economia e à população cametaense em geral, diminuindo a produção do pescado em até $60 \%$. Com isso, essa produção deixou de ser suficiente para atender à demanda do município. O peixe, que antes existia em fartura e podia ser exportado para outros lugares, agora não consegue suprir às necessidades da comunidade local, tendo que ser importado de outros municípios da região, como afirma o representante da Colônia de Pescadores de Cametá: "Com a barragem de Tucuruí, 50\% das espécies de peixes sumiram, e $60 \%$ do peixe consumido em Cametá vem de fora, como Tucuruí e o Baixo Amazonas [sic] 
como Porte." (2002).

Para tentar amenizar os problemas gerados com a construção da hidrelétrica, a colônia de pescadores de Cametá cria peixes em cativeiro e pressiona a Eletronorte para financiar um projeto de criação de um laboratório que possa possibilitar o repovoamento dos rios.

A relação mais direta da colônia de pescadores dá-se com outras instituições governamentais e não-governamentais, tais como o Ministério do Meio Ambiente, a Secretaria do Meio Ambiente e a Associação Paraense de Apoio às Comunidades Carentes - APACC, não se fazendo presente dentre elas a Universidade Federal do Pará. A relação entre essa colônia e a UFPA existe apenas em algumas questões pontuais, não havendo nenhuma parceria formal, nada instituicional.

A citada colônia de pescadores tem projetos financiados pelo Ministério do Meio Ambiente para reflorestamento, produção de mudas e piscicultura, tendo como objetivo principal o reflorestamento das ilhas. Mantém relação muito grande com a Universidade Federal Rural da Amazônia (UFRA), dela recebendo cursos de formação.

Constatamos que a relação da UFPA com a Cooperativa Agrícola Resistência de Cametá (CARC) não era diferente daquela que a universidade mantinha com a colônia de pescadores do município, assim como com as instituições governamentais existentes no local. Segundo a direção da CARC, a Universidade Federal do Pará nunca estabeleceu nenhum tipo de convênio com a cooperativa. Existe parceria desta com a Secretaria de Agricultura do município (SEMAGRI), para a criação de laboratório; e com a Faculdade de Ciências Agrárias do Pará - FCAP, para oferta de seminários aos associados.

Destacamos que, apesar de não se ter notícias de nenhum projeto desenvolvido pela UFPA com vistas ao desenvolvimento econômico de Cametá, entidades e instituições cujos representantes foram entrevistados reconhecem a importância dessa instituição no campo do ensino, ao ofertar à população cursos de Licenciatura em Pedagogia, Letras e Artes, Matemática, História e Geografia. Dessa forma, a referida universidade vem contribuindo com o desenvolvimento humano ao apresentar à comunidade científica e acadêmica trabalhos docentes em nível superior, em uma visível tentativa de extinguir a figura do professor leigo no interior do estado.

Embora o povo cametaense reconheça a relevância da UFPA no desenvolvimento social e educacional do município, entende que a instituição tem, ainda, muito a contribuir no que se refere à situação econômica do município e à decorrente melhoria de vida do povo. Porém, lembramos que tal contribuição só será possível se a universidade adequar-se às novas necessidades da população. 
Perguntamos aos nossos entrevistados, egressos de Pedagogia, se a interiorização do ensino superior, através da UFPA, conseguiu atender às necessidades de Cametá. As respostas foram:

"Não; existe carência quanto a variedade de cursos" (2002).

"Sim; sabe-se que o campus de Cametá já formou muitos pedagogos e letrados, mas precisa ampliar sua área de formação para condizer melhor com nossas realidades atuais"(2002).

"Sim; Atualmente contamos com apenas três cursos na área de educação, mas seria importante para nosso município se a U.F.P.A [sic] projetasse cursos na área de saúde e agricultura” (2002).

"Não; não se pode negar que a contribuição da U. F.P. A [sic] para Cametá foi e é importantíssima; no entanto, o pequeno número de áreas de formação ofertadas não atende as reais necessidades do município" (2002).

Diante das respostas transcritas, podemos observar que há unanimidade nas falas quanto ao fato de que a universidade precisa ampliar sua área de atuação, criando cursos que atendam às outras necessidades da população, nas suas diversas realidades.

Analisando as entrevistas realizadas no município de Cametá, com egressos de Pedagogia e representantes da Cooperativa de Agricultores e
Pescadores de Cametá, da EMATER e da SEMAGRI, podemos afirmar que todos reconhecem o papel desenvolvido pela UFPA na área do ensino, embora existam criticas no que se refere à pouca expressividade da universidade dentro da comunidade, como afirma o representante da SEMAGRI:

"A educação teve um ganho em relação ao número de profissionais na área da educação, porém, em termos quantitativos. No qualitativo a UFPA fica a dever, principalmente em virtude do distanciamento do corpo docente de outro lugar com o município, não criando um vínculo desse corpo docente com o município [sic], não criando condições à expansão da pesquisa e do desenvolvimento de projetos para o município. Nesse sentido, o qualitativo se torna deficitário, não oferecendo o que poderia à comunidade." (2002).

Todavia, quando nos voltamos para a área do desenvolvimento econômico, o mesmo reconhecimento não é percebido. Todos os entrevistados são unânimes em afirmar que a Universidade pouco tem contribuído para o desenvolvimento econômico do município, como afirma o representante da EMATER: "não existe nenhum projeto da universidade que vise ao desenvolvimento do campo e do município”(2002).

Constatado o distanciamento da Universidade com as questões eco- 
nômicas de Cametá, fica evidente que é preciso que a UFPA crie novos cursos que visem a atender os diversos setores da economia local, como a agricultura, a pesca e outros. Essa é uma exigência e uma necessidade percebida em todos os setores da economia local, para que o município encontre condições reais de promover seu desenvolvimento, tanto econômico quanto social.

Os entrevistados são unânimes também ao ressaltar que a UFPA ainda tem muito a contribuir com a população cametaense; mas reconhecem que, para que isso seja possível, torna-se necessário que a instituição crie projetos e parcerias com órgãos públicos e com os demais setores da economia local, possibilitando maiores condições e possibilidades ao desenvolvimento econômico racional do município.

Enquanto permanecer a política de distanciamento da UFPA com as questões econômicas do município, universidade e sociedade vão parecer dois corpos estranhos, agindo independentemente, não havendo interação entre ambas. Esse fato faz com que a universidade não seja vislumbrada como possibilidade geradora de respostas aos anseios e necessidades do município.

Diante dessa situação, a universidade não conseguiu despontar como instituição promissora ao desenvolvimento econômico de Cametá; conseqüentemente, não alcançou ainda o reconhecimento da população. Isso se deve ao fato de que a UFPA ainda se encontra muito presa àquilo que se propôs com o projeto de interiorização - a qualificação da docente, não desenvolvendo atividades de pesquisa e extensão pelas quais seria possível manter o diálogo com a sociedade local e, assim, perceber a realidade na qual está inserida.

Em virtude da realidade apresentada, e diante do contato com moradores - filhos de Cametá - fica a impressão de que para grande parte da população a universidade é uma instituição fantasma, cujos avanços são percebidos somente na área do ensino.

Fica evidente que o projeto de interiorização da universidade estava intrinsecamente relacionado com o projeto desenvolvimentista do Governo Federal, assumindo a função principal de qualificar a mão-de-obra docente para atender às novas necessidades surgidas com o processo de industrialização da economia brasileira.

A UFPA poderia contribuir muito mais com o município, por intermédio da implantação de cursos na área da Agricultura e do turismo. Poderia, também, criar um quadro docente próprio e voltar seu currículo educacional para o meio ambiente, o que ajudaria acentuadamente com a realidade econômica cametaense. Dessa maneira, estaria contribuindo de forma direta e em curto prazo com o desenvolvimento do município, oferecendo à sociedade condições reais de 
melhoria de vida.

Mesmo estando reconhecida a importância da UFPA para o município de Cametá, no que se refere ao ensino, a sociedade prossegue reivindicando da universidade o redirecionamento de suas ações quanto às outras áreas do conhecimento, dando ênfase ao tripé ensino, pesquisa e extensão, além da criação de novos cursos ligados as atividades econômicas de atuação da sociedade.

A partir do momento em que a universidade estiver atuando em outras áreas do conhecimento e atendendo às necessidades sociais mais urgentes de Cametá, além daquelas que se apresentam na educação, poderá firmar-se no interior da sociedade. Poderá, então, ouvir os problemas da população e debater sobre eles, apresentando-se como instituição que apresenta propostas de melhorias à comunidade cametaense e despontando como grande fomentadora do desenvolvimento econômico e social do município.

\section{REFERENNCIAS}

BRASIL. Ministério do Desenvolvimento Econômico e Social. SUDAM. I Plano de Desenvolvimento Econômico da Amazônia, 1972/1974.

Ministério do Interior. Fundação

Projeto Rondon. Cartilha da integração. Brasília, 1974.

Ministério do Interior. Fundação Projeto Rondon. A universidade brasi- leira e o Projeto Rondon. Brasília, 1974.

Ministério do Interior. Fundação

Projeto Rondon. Relatório do X Encontro do Programa Campus Avançados. Brasília, 1981.

Ministério do Interior. Linhas de ação do Ministério do Interior no Governo do Presidente Ernesto Geisel. Brasília, 1974.

BECKER, B. K. Geopolitica da Amazônia: a nova fronteira de recursos. Rio de Janeiro: Zahar, 1982.

CARNEIRO, V. L. A questão da educação na Amazônia. Belém: UFPA, 1989. (mimeo).

CARVAlHO, D. M. Políticas e exclusão social: um estudo sobre o município de Cametá/Pa, Belém, 1998

CARTA, M. (Dir.). Amazônia: a perdição do paraíso. Revista Retrato do Brasil, Rio de Janeiro, 1984.CAMARGO, A. M. M. A universidade na região amazônica: um estudo sobre a interiorização da UFPA. Dissertação (Mestrado em Educação) - Universidade Federal do Pará, Centro de Educação/ UFPA, Belém, 1997.COELHO, M. S. C. A interiorização do ensino superior no Pará e o Banco Mundial: um olhar sobre as aproximações destas propostas. Dissertação (Mestrado em Educação) UNIMEP, Piracicaba, 1998.

COELHO. M. C. N. Estado e políticas públicas na Amazônia: a evolução do setor energético e o desenvolvimento sócio-econômico nos estados da Amazônia. Belém: CEJUP, 2000.CUNHA, L. A. O público e o privado na educação superior brasileira: fronteira em movimento? In: TRINDADE, E. (Org.). Universidade em ruínas na república dos professo-

Olhar de professor, Ponta Grossa, 7(2): 35-46, 2004. $\overline{45}$ 
res. Petrópolis: Vozes, 1999. JASTO, A. A planície: fato e crítica. Jornal do Baixo Tocantins, Cametá - PA, v. 8 , n. 1 , mar. 2001.

LOBO, M. A. A. Estado e capital transnacional na Amazônia: o caso da Albrás-Alunorte. Belém, PA: UFPA/ NAEA, 1996.

NAHUM, J. S. A Amazônia dos PDAs: uma palavra mágica? Dissertação (Mestrado em Planejamento do Desenvolvimento) - NAEA-UFPA, Belém, 1999.

PARÁ. I Projeto Norte de Interiorização: documento das instituições de ensino superior da Amazônia, 1986-1989. Belém - PA, 1985. (mimeo).

\section{Projeto Norte de}

Interiorização: documento das instituições de ensino superior da Amazônia, 1994-1997, Santarém - PA, 1993. (mimeo)._. Prefeitura de Cametá. Informe Caamutá. Cametá - PA, ano 1, n. 1 , fev. 2001.

Secretaria de Estado de Planejamento e Coordenadoria de Articulação Municipal. I Plano Anual de Trabalho do Município de Cametá 1981, Cametá - PA, 1979.

SILVA JR, J. R.; SGUISSARDI, V. Novas faces da educação superior no Brasil: reformas do Estado e mudanças na Educação. Bragança Paulista, SP: EDUSF, 1999.

UNIVERSIDADE FEDERAL DO PARÁ. Gabinete do Reitor José Seixas Lourenço. Justificar a interiorização da UFPA. Belém - PA, 1987. 